LICENÇA CC BY: Artigo distribuído sob os termos Creative Commons, permite uso e distribuição irrestrita em qualquer meio desde que o autor credite a fonte original.

\section{PESQUISA EM EDUCAÇÃO AMBIENTAL: POR UMA EPISTEMOLOGIA DA VIDA}

RESEARCH IN ENVIRONMENTAL EDUCATION: TOWARDS AN EPISTEMOLOGY OF LIFE

INVESTIGACIÓN EN EDUCACIÓN AMBIENTAL: POR UNA EPISTEMOLOGÍA DE VIDA

Eliane Renata Steuck ${ }^{1}$

Vilmar Alves Pereira ${ }^{1}$

1Programa de Pós-Graduação em Educação Ambiental, Universidade Federal do Rio Grande, Rio Grande, RS, Brasil.

Artigo recebido em: 04/12/2019

Aprovado em: 14/10/2020

Resumo: Neste artigo, apresentamos os modos de pensar descritos por Heidegger (2003) em diálogo com os modos de pensar do mundo andino (BERMUDEZ, 2016), para discutir elementos de uma ontoepistemologia ambiental (PEREIRA; FREIRE; SILVA, 2019) e que contribuam para uma pesquisa que pretende compreender as relações entre a filosofia, a felicidade e a Educação Ambiental. Os elementos identificados emergiram da escuta e se caracterizam por terem sido elaborados em diálogo com os interlocutores, a partir de narrativas na perspectiva hermenêutica, estando assim organizadas em três categorias: olhar, compreender e conhecer. Parte da compreensão de que viver em um mundo é participar da impermanência das coisas todas, em um projeto inacabado, de verdades temporais e transitórias. Os resultados apontam para a fecundidade da narrativa hermenêutica como possibilidade de elaboração de elementos para a compreensão do ser no mundo, inserindo-os em um debate ontoepistemológico na Educação Ambiental.

Palavras-chave: Educação Ambiental; ontoepistemologia ambiental; hermenêutica.

Abstract: This paper presents the ways of thinking described by Heidegger (2003) in a dialogue with the ways of thinking of the Andean world (BERMUDEZ, 2016), in order to discuss elements of an environmental ontoepistemology (PEREIRA; FREIRE; SILVA, 2019) that have contributed to a study on the relations between philosophy, happiness and Environmental Education. The elements identified emerged from the act of listening, and are characterized by the fact that they were elaborated in dialogue with the interlocutors, based on narratives from the hermeneutic perspective, organized in three categories: looking; understanding; and knowing. Part of the understanding of living in a world is being a part of the impermanence of all things, in a work in progress, made of temporal and transitioning truths. The results point to the fertility of the hermeneutic narrative as a possibility for elaborating elements 
for an understanding of being within the world, placing ourselves in an ontoepistemological debate in Environmental Education.

Keywords: Environmental Epistemology; environmental ontoepistemology; hermeneutics

Resumen: En este artículo, presentamos los modos del pensar descritos por Heidegger (2003) en diálogo con los modo de pensar del mundo andino (BERMUDEZ, 2016) para discutir elementos de una ontoepistemología ambiental(PEREIRA; FREIRE; SILVA, 2019) y que contribuyan para una investigación que pretende comprender las relaciones entre filosofía, felicidad y educación ambiental. Los elementos identificados surgieron de la escucha, se caracterizado por haber sido elaborados en diálogo con interlocutores, a partir de narrativas en la perspectiva hermenéutica, y se organizan en tres categorías: mirar, comprender y conocer. Parte de la comprensión de que vivir en un mundo es ser parte de la impermanencia de todas las cosas, en un proyecto inacabado, de verdades temporales y transitorias. Los resultados apuntan para la fecundidad de la narrativa hermenéutica, como una posibilidad de elaboración de elementos para la comprensión del ser en el mundo, insertandolos en un debate ontoepistemológico en la Educación Ambiental.

Palabras clave: Educación ambiental; ontoepistemología ambiental; hermenéutica.

\section{Da perspectiva da existência: uma possível explicação do por que pesquisar}

[...] viver no mundo não é ocupar um lugar em meio a um ambiente povoado de objetos, mas ao contrário, é juntar-se ao processo de formação e permanente transformação das coisas vivas, humanas e não humanas. (CARVALHO, 2014, p. 77).

Gosto de pensar que viver no mundo é o encontro contínuo consigo mesmo e com o outro, humano e não humano. É ter notícias de si a cada encontro, sabendo-se como quem está sendo e não se impondo os limites de quem se encontra pronto e concluído. É impermanência.

Reflito sobre minha própria existência, na tentativa de reduzir as muitas camadas que foram construídas sobre o Ser e que, não raro, impedem que este Ser se manifeste, que viva sua verdade, que encontre seu espaço de liberdade, que se permita o processo de permanente transformação.

Pode parecer estranho ao leitor e à leitora um artigo - com pretensões de ser científico - escrito na primeira pessoa, com características narrativas e com flashes de experiências pessoais, quando a academia, em geral, exige do(a) pesquisador(a) um afastamento de seus objetos e/ou sujeitos de pesquisa, uma observação neutra dos fenômenos estudados e uma lista considerável de referências bibliográficas.

Este artigo é o recorte inicial do projeto de tese que procura estabelecer uma discussão que leva em conta a felicidade, a partir de um diálogo filosófico acerca das verdades e das crenças que produzimos e às quais nossa sociedade foi sujeita ao longo de décadas, consolidando um modo de ser fragmentado e desconectado de sua ancestralidade, da natureza e de seus elementos essenciais. 
Neste sentido, escrever em primeira pessoa se faz necessário para contar uma história. A história de como o tema da Felicidade vem encontrar a pesquisa em Fundamentos da Educação Ambiental (EA) e como este encontro motivou uma jornada em busca de uma metodologia e epistemologias que considerassem a vida das pessoas, na perspectiva defendida por Vilmar Alves Pereira (2016), de que há um deslocamento no campo da EA que "aponta muito mais para uma compreensão ontológica do que epistemológica na maneira que pensamos e sentimos a EA" (PEREIRA, 2016, p. 78).

Nestes movimentos iniciais, trocar de pele me parece ser a metáfora adequada para dizer que a aventura nos caminhos da Narrativa Hermenêutica tem exigido de mim um profundo exercício de deixar-ser-com. Na perspectiva de uma filosofia existencialista, encontro o pensar que permite a confiança necessária na intuição, de maneira que narrar a existência se traduz em uma possibilidade de compreender o ser no mundo, um ser que só se revela em sua morada (HEIDEGGER, 2007).

Me parece oportuno dizer, considerando que não existe o óbvio, assim como não existem verdades absolutas, que falar de Felicidade exige aproximação consigo mesmo, exige compreender os sentidos em que se dá à existência. Falar de felicidade implica em falar de sistemas de crenças e de contextos culturais, é falar de existência e das implicações dos modos de Ser em um tempo e um espaço. É falar das diferentes fases da vida.

\section{Da lua crescente: a menina}

Como um ser que se coloca no mundo, tenho buscado compreender essa constituição ontológica do ser presença, que se mostra e que, ao mesmo tempo que é-em-si, também deixa-ser-com (HEIDEGGER, 2007).

Sou neta de agricultores. Me acostumei a ouvir histórias e por elas tomei gosto ainda quando criança. Gosto pelas fotografias antigas que, uma a uma, meu avô me contava das pessoas: A "Deutsche Schule", a escola somente para alemães, em que estudou. Pequenino e magro - sentia fome -, me contava ele, que aprendeu português por ser proibido de falar alemão naqueles anos. A irmã, em pose de artista de cinema - porque tirar fotografia era um evento. Passávamos horas olhando os pequenos quadros de moldura verde que se enfileiravam nas paredes da sala.

Os casamentos dos filhos, vestidos de noiva e de noivo. Circulei muitas vezes à procura da fotografia do casamento de minha mãe - a mais vaidosa das filhas - contava meu avô, disfarçando o sorriso. Contava como quem apenas constatava: era vaidosa. Diziam da saia do uniforme da escola - daquela que só cursou até a terceira série do então primário - que era tão engomada que permanecia esticada todo o tempo.

A mais vaidosa teria fotos de seu casamento, por certo! Circulei muitas vezes antes de me encorajar a perguntar. A resposta foi uma mentira qualquer. Dessas que se contam para crianças, porque acreditam que "são apenas crianças". A pouca frequência com que via meu 
pai e a ausência daquela que seria a foto mais importante da vida de minha mãe denunciavam algo que eu, ainda pequena, sentia que não queria saber. Me bastava viver: as coisas são o que são. Os adultos que complicam tudo. Vão se enchendo de camadas, criando couraças até que se esquecem de quem são.

Hoje, gosto de olhar o céu e acompanhar os ciclos da lua, permitindo que cada fase sua se processe, também, em mim.

\section{Lua cheia: a mulher que gesta}

E é nesta condição de humana, com o propósito de contribuir nos movimentos de cura deste planeta adoecido, que me encontro diante das inúmeras possibilidades de caminhos e respostas, que se elaboram em um tempo e, com ele, tem a necessária intimidade.

É de minhas próprias experiências, das memórias que atravessam meu corpo, que se manifesta meu desejo pela pesquisa, que ensaio a coragem de ousar e errar, que materializo as palavras em textos.

Nesta tarefa de conhecer, sempre incompleta, encontro refúgio nas (in)certezas e verdades provisórias, na finitude que habita o tempo, na linguagem como condição ontológica. E é nessa tarefa de analisar a mim mesma que (re)elaboro compreensões e ressignifico experiências quanto aos seres que coabitam este Planeta, finito e fecundo.

Situo esta reflexão inicial, em minhas próprias questões, como temas que se lançam ao aberto e, nesta condição, se abrem ao diálogo. Diálogo com o outro, comigo, com os fatos, com as coisas todas. Diálogo como atributo da existência de que "o que se dá na linguagem dá-se também no todo de nossa orientação vital: o fato de estarmos familiarizados com um mundo convencional pré-formado" (GADAMER, 2004, p. 236).

Dito isto, é preciso informar ao leitor em que terrenos tenho ancorado os pensamentos que insistem em se lançar ao vento, qual solo fecundo orienta estes mesmos pensamentos que ora se fazem palavra. E como o tenho realizado, em tímidos passos, por vezes à luz de lamparina'.

Empresto da enfermagem, profissão em que tive meus primeiros encontros com as inúmeras possibilidades de encolhimento da dignidade da vida (Freire), a metáfora da luz e da sombra, pelos rasgos de luz de lamparina, para dizer da condição de ser aí (HEIDEGGER, 2006), de mostrar-se e esconder-se na-com-pela linguagem (GADAMER, 2004).

Estou grávida de mim. Grávida das conversas improvisadas pelas ruas com desconhecidos, dos abraços amorosos como meus afetos, dos diálogos profundos com colegas que vislumbram na pesquisa um caminho. Uma gestação nutrida pelos pés descalços pelas areias da praia do Cassino $^{2}$, pelos ventos que sussurram os segredos que vim buscar, pelo calor das casas nas noites frias.

Encharcada de vida, é na pesquisa em Fundamentos da Educação Ambiental que me preparo para parir - apoiada pelas mãos, pelos saberes e pelos afetos dos próximos e dos 
que me precederam com suas pesquisas - a interpretação da existência do outro, a partir da expressão de minha própria existência.

E escrevo, porque escrever é preciso. Escrevo por acreditar que não sei o necessário sobre a felicidade, nem da filosofia, nem da Educação Ambiental. Se ousasse acreditar que já sei o suficiente, o que se mostra já não me ofereceria espanto e

[...] talvez por isso nos seja tão difícil adquirir familiaridade com uma questão nascida de uma verdadeira experiência. Para que isso aconteça, é preciso poder espantar-se diante do simples e assumir esse espanto como morada. (HEIDEGGER, 2002, p. 228-229).

A partir do pensamento de Heidegger (2002), ter o espanto como morada implica em não cair na armadilha de reduzir o saber a um ciclo de repetições, mas olhar o que todos olham e enxergar o que poucos enxergam, encontrando espaços e campos ainda não explorados.

\section{Da lua minguante: o recolhimento necessário para olhar em si mesma}

Me recolho à profundidade do ser que habita em mim. Na floresta negra de minhas reflexões, encontro o lenhador - como refere Hannah Arendt (1987) a respeito do pensar de Heidegger - que mostra da vida o sentido de existir, que segue o caminho que desbravou, como um presente, recebido do fazedor de machados (ORSTEIN, 1998).

Reinsisto em pensar o corpo. Um corpo que se mostra e que se esconde. Assim como tantos que circulam em vaivém. Corpos dominados, desencorajados, silenciados em sua verdade, sua força vital. Corpo que, na impossibilidade de expressar seu sofrimento ou até impossibilitado de senti-lo, o traduz em violentas e descartáveis relações.

E por que discorrer sobre as questões que me ocupam em pensar e sentir, confidenciar a transmutação necessária e latente para, sem aviso, explorar o corpo e sua (im)possibilidade de se mostrar? Porque é nestes atravessamentos corpóreos que encontro pouso e me inquieto. É esse corpo que experiencia os acontecimentos e é nele que são ressignificadas.

No entanto, entendo que falar de felicidade de maneira ingênua, acrítica, descontextualizada, ou desconsiderando "as zonas de sacrifício" (LAYRARGUES, 2012, p. 414) a que são empurradas parcela da sociedade que não pertence às elites, seria negligenciar a oportunidade de discutir o tema, que mesmo estando entrelaçado nas pesquisas e práticas em EA e bem apropriado pelos artifícios da propaganda de estímulo ao consumo, pode oferecer outros horizontes aos fundamentos da Educação Ambiental.

E, nestes movimentos, sou impulsionada pela ideia de uma estética da felicidade, que compreendo como um condicionante das escolhas não conscientes de consumo. Considero que o perfil de consumo vem gradativamente se transformando e, ainda que mantendo o objetivo de satisfação de necessidades - biológicas ou forjadas -, visto que a "felicidade instituída está indexada ao poder de consumo" (PASSOS, 2018, p. 15), transita para a aquisição 
de bens e serviços que, a princípio, chamarei de espirituais.

A tudo parece ser possível consumir, inclusive a Felicidade. Uma felicidade pronta para consumo, sem a necessidade de percorrer os caminhos da floresta e nela habitar, mas que se ocupa de percorrer os caminhos da mídia e do mercado. Caminhos tomados por uma racionalidade instrumental e utilitária, onde o ser se entifica - para usar das palavras de Heidegger - e cede à hegemonia.

Nesta lista de bens e serviços, considero desde os medicamentos, que se apresentam como solução às dores produzidas na contemporaneidade, até os espaços de atendimento que oferecem serviços como, por exemplo, as massagens, e os profissionais que oferecem aprendizagens sobre felicidade, sobre relacionamento, sobre sucesso. Há todo o tipo de técnica para a reparação da dor e da superação do fracasso, seja no amor, na profissão ou nos estudos.

E neste caminho se aposta também na longevidade. A ideia é viver mais e, quem sabe, contornar a finitude que nos espreita logo na esquina. Birman (2012) afirma que há um mal-estar contemporâneo que se caracteriza pela dor e que tal condição, diferenciada do sofrimento, estaria inscrita na razão pela qual o indivíduo fecha-se em si mesmo, revelando uma subjetividade contemporânea narcísica e solipsista. O autor discute a relação entre as dores provenientes deste mal-estar contemporâneo com a incapacidade da sociedade de criar mediações no mundo.

E se estamos impossibilitados de criar mediações no mundo, estamos impossibilitados de produzir sentidos de existência e nos tornamos seres impróprios, seres desprovidos de sua autenticidade. Humanos, mergulhados em patologias sociais, forjadas em um projeto econômico, político e cultural (SOUZA, 2010) do ocidente, que estabelece um parâmetro para o desejável sucesso, que impelidos a agir de maneira permanente em nome de um futuro, se encontram cada vez mais vulneráveis ao esvaziamento dos sentidos de suas próprias vidas.

Vivemos uma vida inautêntica, de negação de si mesmos, mergulhados em nós mesmos (HEIDEGGER, 2007). Heidegger via na angústia a essência da existência do homem. Só o homem está capaz deste sentimento. É o que faz o homem ultrapassar a barreira do ser, emergir e se colocar como ser aparente no mundo e, finalmente, viver uma vida autêntica. Talvez uma compreensão pessimista da existência, se comparada com a utopia obsoleta da felicidade.

Mas uma utopia que prefiro compreender como a constante possibilidade de espanto, lugar onde podemos fazer morada, de "deixar-se levar por deixar-se com-vocar por" (HEIDEGGER, 1979, p. 219-220).

\section{Da lua nova: tempo de plantar}

La cura de la existencia humana está en la felicidad, más que en el cumplimiento de una deontología del deber-ser, en una ética de las virtudes y del bien común, en una responsabilidad y deferencia hacia el otro. Estar contento no es ser feliz. La moral es consustancial a la condición humana, pero no basta para procurarnos la felicidad. Más que un estado de bienestar económico, la felicidad es el antídoto ante al desasosiego y la desesperanza; es sentirnos bien dentro de nuestra piel, sutil membrana que nos pone en contacto con el mundo y con los otros. (LEFF, 2007, p. 41). 
Para iniciar as reflexões, realizei buscas por pesquisas de trabalhos que relacionem a felicidade à sociedade e ao ambiente. Nestas buscas, identifiquei que, embora a Felicidade seja pauta comum à sociedade e a mídia se utilize de diferentes estratégias para vender um padrão de felicidade, a academia ainda não se dedica ao tema assim como se ocupa de pensar o conhecimento.

Para esta afirmação, encontro sustento nas palavras de Leff (2007), para quem a

[...] filosofía occidental ha indagado el ser de las cosas, el conocimiento, la economía (el oikos), la ética de lo bueno y del bien, la estética del mundo sensible: de las formas, del sonido y el color. A través de lo lúdico y lo erótico, la metafísica se asomó a la felicidad. Pero no la nombró, no la tematizó, no la indagó, no la generó. (LEFF, 2007, p. 41).

Encontrei discussões sobre o conceito de Bem Viver dos Andes e como estes saberes ancestrais influenciaram as Constituições do Equador e da Bolívia. Com relação ao Bem Viver, Boff (2013) acrescenta que:

[...] a democracia comunitária, exercida pelas culturas andinas nas quais o sentido comunitário é determinante; as comunidades articuladas entre si participam das decisões coletivas, acentuando sempre a busca do equilíbrio entre todos e com as forças da natureza em função do bem viver; por fim segundo alguns, estaríamos rumando na direção de uma "superdemocracia planetária". (BOFF, 2013, p. 126, grifos do autor).

Destas leituras, novas reflexões se manifestaram e, entre elas, destaco uma nova questão: Quais as possíveis contribuições que a filosofia latino-americana pode trazer aos fundamentos da EA? Em que medida este Bem Viver, instituído por lei, representa o bem viver das pessoas?

Tais reflexões ganham força a partir do pensamento de Layrargues (2012), que constata que há, no cenário latino-americano "[...] uma nova onda de resistência política e cultural, presente nas culturas indígenas latinas, manifestada pelo conceito do Buen Vivir. Há quem, inclusive, advogue a favor da criação de um Pensamento Ambiental Latino-Americano" (LAYRARGUES, 2012, p. 415).

Ainda sobre o pensamento latino-americano, concordo com a reflexão de que "o começo do filosofar desde América Latina é o pensamento indígena milenar, a invasão, exclusão e destruição das suas culturas e a imposição de uma cultura que começa com os pré-socráticos [...]" (CABRERA; ALVES, 2013, p. 10) e contribuiu para o esquecimento de tais saberes.

As expressões allin kaway e hawka kay, apresentadas na última parte da tese de Bermúdez (2016), evidenciam a importância de que compreender seus sentidos pode contribuir para compreender uma categoria andina que remete à alegria, que se apresenta como possibilidade de compreender uma estética da felicidade para estes povos, mas que carrega de outros sentidos o Buen Vivir.

Com relação à expressão "Otros interlocutores han ido confirmando que lo que se busca en el mundo andino no es allin kawsay, que se podría traducir como 'buena vida o vida buena', sino 'la justicia y la paz'" (BERMúDEZ, 2016, p. 351). Isto significa dizer que o bem viver não está dissociado de ter boa saúde, viver em justiça e estar em paz. No entanto, não é possível estar em paz se não se possui o necessário para a vida. 
¿Cómo puede haber tranquilidad cuando el mercado impone criterios de selección de los productos sin que haya una adecuada capacitación y conocimiento de las reglas de juego? ¿Cómo puede haber paz cuando hay una amenaza del uso del agua y de los suelos por parte del Estado sin una consulta necesaria? (BERMÚDEZ, 2016, p. 353).

A reflexão de Bermúdez (2016) remete à discussão de Layrargues (2012) acerca das macrotendências da Educação Ambiental, em que se questiona "qual projeto societário a Educação Ambiental brasileira deseja construir?" (LAYRARGUES, 2012, 414) e defende a Macrotendência Crítica como a que "[...] aparenta apresentar respostas adequadas para transformar sociedades desiguais e insustentáveis" (LAYRARGUES, 2012, p. 410, grifos do autor).

Recorro, ainda, às palavras de Freire (1987), para quem, dentro de uma

[...] visão inautêntica de si e do mundo os oprimidos se sentem como se fossem uma quase "coisa" possuída pelo opressor. Enquanto, no seu afã de possuir, para este, como afirmamos, ser é ter à custa quase sempre dos que não têm, para os oprimidos, num momento da sua experiência existencial, ser nem sequer é ainda parecer com o opressor, mas é estar sob ele. É depender. Daí que os oprimidos sejam dependentes emocionais. (FREIRE, 1987, p. 32).

Dito isto, reafirmo que discutir a Felicidade, neste contexto, não me parece algo simples. Não se trata, apenas, de religar aos sentidos sagrados da natureza ou discutir os sentimentos que movem o consumo, mas de empreender esforços em compreender os processos cotidianos, inclusive de luta pela sobrevivência, pois, me parece, que onde não há justiça não há bem viver³.

\section{Do olhar: tempo de compreender outros mundos}

¿Por qué llamar a la felicidad al debate de la educación ambiental? Precisamente porque reina la infelicidad, el desasosiego, casi la desesperanza, en la era del vacío, del riesgo y la incertidumbre; de la pérdida de referentes y del sentido de la existencia. (LEFF, 2007, p. 40).

Pensar uma epistemologia da vida exige pensar uma pesquisa que dialogue com a vida, com a existência e - talvez seja uma utopia própria dos que acreditam - com as possibilidades de existência. E outras novas questões se manifestam: Quais são e existem metodologias próprias da EA? Quais caminhos a pesquisa em EA percorre para lograr suas respostas? Uma pergunta que, a princípio, me parecia que exigia uma resposta.

$\mathrm{Na}$ perspectiva de que o caminho se faz caminhando (FREIRE; HORTON, 2003), foi caminhando, nas Ruínas de Sondor, em Pacucha, província de Andahuaylas, no Peru, que me recordei de todas as pessoas com quem conversei sobre meu interesse de pesquisa e como as conversas se desenrolaram. E, como nas palavras poéticas de Antonio Machado, poeta sevilhano, estive fazendo o caminho.

Caminante, son tus huellas el camino y nada más; caminante, no hay camino, se hace camino al andar. Al andar se hace camino, y al volver la vista atrás se ve la senda que nunca se ha de volver a pisar. Caminante no hay camino sino estelas en la mar [...]. (MACHADO, 1983).

Como cada um, do seu jeito, tinha algo para falar sobre a felicidade, me lembrei da amiga que dizia que bastava falar de meu tema de pesquisa que já fazia novos amigos. E 
me dei conta que as pessoas falavam livremente, ou, popularmente, "soltavam a língua". De maneira que eu pouco falava depois de dizer a palavra "felicidade".

O senhor da livraria em Andahuaylas, que mudou de Lima há sete anos e tem depressão, e que por essa razão gosta de conversar com as pessoas, dizia que não podia se sentir feliz quando gasta muito dinheiro. Quando gasta mais do que tem ou quando percebe que poderia ter guardado um pouco. E que, mesmo sabendo que isso o deixa infeliz, continua fazendo. $E$ termina dizendo que faz coisas para não ser feliz e que precisa mudar. E me olha e diz que tem que mudar porque dá para mudar [...] é só querer [...].

E Raul, que tem uma tienda no Mercado Modelo, que fala de como o governo (não) cuida de sua população. E compara o governo a um pai que planta bananas e batatas e vende a seu vizinho por 5 soles a saca e para seu filho a 20 soles.

Que um pai não pode entregar o que tem de melhor a estranhos e fazer seu filho pagar mais que os estranhos. E usou como exemplo o gás de cozinha, que é exportado por um valor inferior ao que é vendido ao povo peruano, os "filhos" deste governo.

Ou o senhor que podava árvores em Chicmo que, quando perguntei se era ele que cuidava do parque, me respondeu que estava cuidando de seus ancestrais, as plantas. Do parque saí com a primeira foto com as pessoas que vivem esse lugar e as bendiciones da Señora Marcelina.

Ou Rocio, a señora da tienda de oferendas a Pachamama, que me dizia que as pessoas não estão encontrando felicidade em estar com sua família, mas em ter dinheiro. E ela completa que dinheiro pode ajudar a conseguir coisas: com dinheiro se pode comprar uma torre. Para ela, as pessoas estão sempre querendo dinheiro - ao passo que a mesma abre um parêntese - para dizer que não está falando das pessoas que precisam de dinheiro, porque lhes falta para viver. Mas fala das pessoas que têm o suficiente e sempre querem mais. E segue dizendo que os governantes não são políticos, são psicopatas, pois sabem que estão fazendo mal às pessoas e o fazem assim mesmo.

Ou, ainda, a señora sentada no chão em frente a um restaurante na Laguna Pacucha, que meu olhar adestrado apenas viu uma mulher sentada no chão e, em suas referências de memória, entendeu que estaria pedindo dinheiro para comer, quando, na verdade, era ela quem me oferecia comida.

Ou, ainda, Professor Luiz Mujica, que se interessa em saber o que é a felicidade para os jovens de Andahuaylas e me dá pistas que acredita que a felicidade pode estar relacionada com a percepção de natureza que estes jovens têm.

E Maria, estudante da carreira de Educação da Universidade Jose Maria Arguedas, que leu algumas coisas sobre o que seria a felicidade e me conta que concorda com a ideia de que estaria relacionada a um propósito de vida. Não um projeto, salientou ela, porque um projeto de vida não é um propósito de vida. 
Ou as caminhadas na Plaza de Armas, onde observava as famílias, pessoas em grupo ou sozinhas, sentadas, conversando ou somente contemplando, me sinalizando que viviam uma outra relação com o tempo e que, quem sabe, estariam aproveitando melhor o tempo, vivendo melhor a vida (PEREIRA, 2016).

E compreendi que pensar uma epistemologia da vida exige a própria vida, buscando elementos para a compreensão de uma ontoepistemologia ambiental. E tal caminho se faz, fazendo, e superando a intenção de compreensão da existência, precisa voltar ao ser, pois, como afirma Leff, a

[...] reflexión sobre el mundo se renueva desde el pensamiento doloroso de la existencia humana, más allá del propósito del lluminismo de la razón de liberar al hombre y alcanzar un mundo feliz en la transparencia del mundo a través de la ciencia. El existencialismo es una ontología del ser que pasa su existencia curándose. Pero la vuelta al ser no devuelve la felicidad perdida por una nueva comprensión del mundo. La voluntad de poder vivir no es receta alguna para la felicidad. (LEFF, 2007, p. 41).

Por esta razão, apresento estes elementos - ainda que na primeira pessoa - como um movimento realizado a muitas mãos, pelas pessoas que, mesmo que por poucos instantes, caminharam ao meu lado, como sendo um caminho de pistas, um jogo de ludo, que muito me agradava na infância.

No jogo de ludo, um jogo de tabuleiro, poderiam jogar até quatro crianças de cada vez. Cada uma escolhia uma cor e a elas equivaliam quatro peças. Lançávamos os dois dados e o resultado da soma dos dois eram quantas casas poderíamos andar com uma peça de cada vez pelo tabuleiro. O objetivo era colocar as quatro peças dentro de suas casas. O problema era que, ao estar próximo, era preciso contar com a sorte para que os dados the oferecessem o número exato para entrar e permanecer na casa. Porque se fosse maior, você teria que entrar e não poderia permanecer: era necessário voltar tantas casas quantos fossem a contagem determinada pelos dados.

Ou seja, cada vez que estávamos perto de lograr êxito, tínhamos que voltar a algum ponto e refazer o caminho.

A sorte, nesta pesquisa, me parece ser o exercício de olhar e compreender, traduzir e devolver à existência mais do que pensar nela própria, a possibilidade de pensar a felicidade (ou seriam as felicidades?).

\section{Uma epistemologia da vida ou uma ontoepistemologia ambiental?}

A percepção de uma crise de fundamentos da/na EA trouxe ao campo a possibilidade de reivindicar para si novas possibilidades de sentir e pensar, de maneira a "compreender que existe multiplicidade de forma e de sentidos nas relações ambientais" (PEREIRA; FREIRE; SILVA, 2019, p. 6). 
Para os autores,

[...] uma Ontoepistemologia Ambiental de horizonte hermenêutico pode contribuir para o desenvolvimento de uma epistemologia compreensiva, na qual todos os elementos da ampla experiência humana estejam entrelaçados, reconhecendo os múltiplos espaços ontológicos e psicológico-culturais. Nessa perspectiva, reivindica-se uma compreensão das questões ambientais a partir de uma concepção de homem integral, apontando para sua condição ontológica mais abrangente. (PEREIRA; FREIRE; SILVA, 2019, p. 7, grifos do autor).

Na tentativa de ampliar a discussão, apresento elementos que se manifestaram a partir das narrativas, sem necessariamente apresentá-las na ordem em que se revelaram ou que delas faço uso e, menos ainda, com a intenção de elaborar uma ordem de importância, mas, sim, como um caminho que se insere no campo do possível.

Compreendendo a Ontoepistemologia Ambiental como "um modo de ser e de fazer ciência que considere nas suas múltiplas relações a totalidade da dimensão existencial humana e não humana presente no universo" (PEREIRA; FREIRE; SILVA, 2019, p. 7), discuto os elementos constituintes de uma pesquisa em EA que considere tais relações, assim como os "valores estéticos, éticos, espirituais, políticos, históricos e sociais" (PEREIRA; FREIRE; SILVA, 2019, p. 7) presentes na própria dimensão ambiental.

\section{O compreender}

La felicidad se entreteje en las formas de ser en el mundo. Podemos pensarla, pero la constatamos como un "sentirse en el mundo" Está reservada a la intimidad, a la autogestión de la vida de cada persona, al arte de savoir vivre. (LEFF, 2007, p. 43).

E se a felicidade está entrelaçada com as "formas de ser", um "sentir-se", compreendê-la passa por compreender os modos de ser no mundo, a partir da compreensão da existência dos modos de ser que vão se expressando na cotidianidade, nas relações com o outro e, inclusive, na condição de inacabamento, temporalidade e finitude deste ser (HEIDEGGER, 2007).

Um movimento de interpretação de um ser que, ao mesmo tempo que interpreta a si mesmo, é interpretado. E, por autointerpretação, vai se transformando, se constituindo e atribuindo significados às suas expressões no mundo.

Considerando os humanos como intérpretes do mundo, a linguagem se apresenta para além de um instrumento e se constitui como atributo criativo que torna possível reinventar identidades, em um movimento de resistência à unidade hegemônica, à totalidade dominante.

De maneira que esta interpretação não é ingênua ou isenta de percepções próprias, mas fruto de referências da própria memória e dos processos a que se vá submetendo em sua própria existência. Assim que compreender exige aceitar seus preconceitos e suas limitações. Compreender exige reflexão sobre a própria ação, em diálogo com a ação do outro.

Por concordar com Heidegger (2007), que não há uma essência humana única e com Bermudez, que "la vida en la Tierra depende, entonces, de la manera de entendernos a nosotros mismos en el seno de la pachamama donde vivimos inexcusablemente" (BERMUDEZ, 2016, p. 
70), este exercício de compreender exige que meu olhar se projete junto ao olhar do outro, em um exercício de olhar-com.

\section{Do olhar}

E como olhar-com quando nosso olhar está forjado para a objetificação do outro? Como superar a dicotomia entre saber e sentir, como se tais processos se dessem alheios ao corpo que experiencia o existir? O corpo, espaço de atravessamentos dos sentidos, o primeiro contato com o mundo, com o outro. É a pele que habitamos e onde produzimos os sentidos que atribuímos às coisas todas que conhecemos e que imaginamos conhecer.

Não é possível habitar a pele do outro e, por esta razão, criamos, como sociedade, uma expressão que nos remete à capacidade de se colocar no lugar do outro para sentir o que sentiria esta outra pessoa: empatia.

Mas que nível de identificação é necessária para que indivíduos, com diferentes modos de ser, carregados de memórias distintas e, portanto, diferentes experiências, possam sentir o que outro sente, de maneira que uma rede de conexões se manifeste e, assim como o calor ${ }^{4}$, os sentires se dissipem de um corpo para outro?

Talvez esteja aí o grande desafio. O que exige a aproximação das pessoas e seus espaços de vida. Uma aproximação que transcende o método, justamente por sua exigência de deixarser-com-o-outro. Aqui, o compreender passa pela resposta à pergunta: Estás vendo o que eu estou vendo? E, por essa razão, elegi como caminho para acessar estes olhares a captura de imagens, em vídeo ou fotografia. Me interessando ver o que o outro vê para pensar-sentir-com.

\section{Do conhecer}

Los sujetos no somos seres autónomos que pensamos desde nuestra interioridad. Somos pensados por Otro, hemos interiorizado un pensamiento que no solo ha alimentado ideologías, filosofías y ciencias, sino que se ha hecho carne, cuerpo, sensibilidad y angustia. Hemos internalizado una prohibición de ser, de ser libres y ser felices. (LEFF, 2007, p. 45).

Para Heidegger (2003), três formas de pensar orientam o conhecimento: o empírico, o pensar dos entes; das regras e condições da lógica; e o filosófico. Na cotidianidade é comum nos afastarmos do pensar filosófico, de maneira que o ente encobre o ser, o objetificando, conferindo a ele seu status por uma utilidade ou sua condição de materialidade. Pensar é o modo de existir, de maneira que cada um de nós, a partir de seu modo prático de existir, produz suas compreensões e as manifesta no mundo. Portanto, não é o mundo que nos determina e produz nossas crenças, mas o sentido que projetamos e, ao projetar, ocultamos e esquecemos do Ser. Assim, o conhecimento se constrói a partir de uma condição criada pelo sentido, enredados na cotidianidade e no que consideramos como real: nossas representações disponíveis das coisas todas, como se estas não tivessem passado ou futuro. 
[...] a aporia consiste no fato de ele (o ser-aí) ser sempre reconduzido aos caminhos por ele mesmo abertos, aferrando-se a seus percursos, enredando-se no já percorrido, traçando nesta rede o círculo do seu mundo, emaranhando-se com a aparência e trancando-se assim ao ser. Dessa forma ele se agita numa atividade febril, virando-se e revirando-se dentro de seu próprio círculo. Tudo o que se opor a esse círculo, poderá excluir do raio de sua atividade. (HEIDEGGER, 1978, p. 232).

De tal maneira podemos nos revirar dentro do próprio círculo, que corremos o risco de ocultar a originalidade da experiência possível ao Ser. A proposta, nesta categoria, é a possibilidade de permitir que o ser se mostre, se manifeste, para além das teorias e dos conceitos preestabelecidos, pois

[...] ao buscar a gênese ontológica do comportamento teórico, perguntamos: quais são, na constituição do ser do ser-aí, as condições de possibilidade existenciais necessárias para que o ser-aí possa existir na forma da investigação científica? A colocação dessa questão aponta para um conceito existencial da ciência. (HEIDEGGER, 2007, p. 375).

É permitir que o que está escondido e esquecido pela cotidianidade se manifeste, abrindo possibilidades para que o Ser se expresse em sua originalidade.

Tendo por horizonte que o conhecimento só pode ser compreendido se considerada a sua conexão com a existência, é importante a reflexão de Bermudez quanto à assertiva de que "el conocimiento tiene muchas formas, que responden a las necesidades de las personas y sus pueblos" (BERMUDEZ, 2016, p. 126) e que, na perspectiva de uma epistemologia andina, vão se organizar em categorias interdependentes, cuja distinção só é possível "pensando juntos [...] con los que tienen voluntad de tomar consciencia de su propia existencia [...] en un mundo difícil de vincularse [...] y dominar" (BERMUDEZ, 2016, p. 148).

\section{O conhecimento da ação prática}

Trata-se da ação prática que só pode ser exercida por um humano em sua existência. Um conhecimento que se produz pelos sentidos da ação cotidiana e que se incorpora ${ }^{5}$ ao seu modo de ser. No entanto, tal categoria apresenta limites, ou nas palavras de Bermudez (2016, p. 129), "la capacidad hacedora del runa ${ }^{6}$ también tiene límites y este se da cuenta de que no pode hacer todo".

\section{O conhecimento da experimentação}

Um conhecimento especializado, que não se pode encontrar repetido em outra pessoa. É um saber que "se constituye, entonces, en una suerte de experticia y de sentido común que sirve para resolver diversos problemas que la vida depara" (BERMUDEZ, 2016, p. 130) e que é resultado de um conjunto de ações que se situam no campo da experiência, em geral relacionadas ao costume, ao hábito.

Neste momento do conhecimento, alcançar a expertise exige olhar e fazer, como também praticar e conhecer as técnicas. É um conhecimento aprendido por procedimentos da vida prática. 


\section{O conhecimento da interpretação}

Um conhecimento que se relaciona com a capacidade de perceber, "un tipo de conocimiento que implica tener a la vista un conjunto de informaciones, las que pueden ser articuladas adecuadamente y e proponer la posibilidad de realización de un hecho o fenómeno" (BERMUDEZ, 2016, p. 137).

Nesta categoria, os que conhecem ou sabem podem ser qualquer pessoa que, com as informações adequadas, faz a leituras dos signos, e que, por esta razão, tem a percepção das coisas. É o conhecimento dos atravessamentos corpóreos, para além das sensações e da prática e que se insere em um campo hermenêutico.

É a capacidade de pensar a técnica e, por esta razão, é possível interpretar, refletir, de maneira a produzir outro conhecimento. Ao passo que ainda, nesse sentido, os modos de pensar para produzir conhecimento têm implicação não somente nos modos de pensar a pesquisa, mas em compreender como as pessoas elaboram seu conhecimento e como o expressam ao mundo, ou como o ser-aí se manifesta.

\section{Das escolhas}

Compreender, olhar e conhecer horizontes que me permitam a aproximação com a busca pela Felicidade e as possíveis pistas para os Fundamentos em EA se traduzem em um dos maiores desafios que já aceitei da vida. Por esta razão, esta tese vem sendo gestada com amorosidade, enredada em minha própria existência.

Pensar uma metodologia talvez não fosse necessário, visto minha escolha por uma postura Hermenêutica diante das possibilidades que se apresentam. No entanto, senti a necessidade de expressar um caminho a percorrer, cujas pistas foram oferecidas pelas pessoas com quem me encontrei. Pessoas anônimas, dessas que são as que fazem a vida acontecer. Essas que, em sua cotidianidade, estão, na maior parte do tempo, presas ao pensar que encobrem o Ser.

Trato desta metodologia como "coletiva", por ter sido pensada filosoficamente por muitas pessoas. Abordo esse pensar como filosófico, por compreender que cada uma delas, neste momento de diálogo, transcendeu sua cotidianidade para pensar-com-na-existência.

Este caminho de investigação se manifesta como resultado de uma imersão em Andahuaylas, província do Departamento de Apurímac, no Peru, onde procurei me acercar de jovens estudantes e da cosmovisão andina e suas epistemologias, onde, conforme Pereira, se "expressam cosmovisões que necessitam ser estudadas, aprendidas e praticadas" (PEREIRA, 2016, p. 18).

Por todos os motivos expressos, em uma proposta de pensar-com, esta investigação em gestação se orienta pelo exercício do olhar, compreender e conhecer. 


\section{Do tempo de começar}

Em geral, um artigo apresenta conclusões, que são apontamentos, cuja fundamentação teórica, articulada aos dados, oferecem respostas a uma questão orientadora da pesquisa. $O$ momento em que o círculo por onde se moveu o/a pesquisador/a se revela em sua totalidade temporal. O momento em que o pesquisador sai do círculo.

Compreendo este tempo como o momento de entrar no círculo e mover-me a partir das coisas como elas se apresentam. As coisas que são e, por serem, estão carregadas do tempo e da história própria deste tempo, na perspectiva "de uma ontologia hermenêutica associada a uma epistemologia hermenêutica, configurado o sentido de hermenêutica enquanto processo permanente de interpretar e compreender o mundo, não como exercício teórico, mas como modo de ser, como vida" (PEREIRA, 2016, p. 38-39).

A partir das narrativas em uma perspectiva hermenêutica, a discussão de tais elementos pretende contribuir para novos horizontes no campo dos Fundamentos da Educação Ambiental, considerando aspectos que, como já apresentados, sinalizam o deslocamento do modo de pensar da ciência positiva para o reconhecimento da dimensão ontológica dos seres (PEREIRA; FREIRE; SILVA, 2019) de maneira a inserir novas possibilidades para o debate ontoepistemológico na EA.

Neste sentido, a pretensão sobre a qual me debrucei foi a de contribuir para superar as prisões do intelecto a que são submetidos os conhecimentos que, por um lado, são negligenciados; por outro, usurpados e convertidos a serviço de um conhecimento dominante, ao utilizar de narrativas na perspectiva hermenêutica, para uma aproximação do ser que está no mundo e é com o mundo.

\section{Referências}

ARENDT, Hannah. Homens em tempos sombrios. São Paulo: Companhia das Letras, 1987.

CABRERA, Júlio; ALVES, Rafael (Orgs). Cartilha de filósofos da américa latina: Pensamentos desde América Latina e filósofos latino-americanos. Brasília: FIBRAL, 2013.

BIRMAN, Joel. O sujeito na contemporaneidade. Rio de Janeiro: Civilização Brasileira. 2012.

BERMUDEZ, Luis Felipe Mujica. Pachamama kawsan: aproximaciones a la naturaleza y sus cambios en Andahuaylas y Chincheros, Apurímac. Tesis de Doctorado. Lima: Pontificia Universidad Católica del Perú, 2016.

BERMUDEZ, Luis Felipe Mujica. Pachamama kawsan: hacia uma ecologia andina. Instituto de Ciencias de la Naturaleza, Territorio y Energías Renovables. Lima: Pontificia Universidad Católica del Perú, 2016.

BOFF, Leonardo. Constitucionalismo ecológico na América Latina. Disponível em: https:// leonardoboff.wordpress.com/. Acesso em: 05 mai. 2019. 
BURKE, James; ORNSTEIN, Robert. O presente do fazedor de machados: os dois gumes da história da cultura humana. Rio de Janeiro: Bertrand Brasil, 1998.

CARVALHO, Isabel Cristina de Moura. A perspectiva das pedras: considerações sobre os novos materialismos e as epistemologias ecológicas. Revista Pesquisa em Educação Ambiental, São Paulo, vol. 09, no 1, p. 69-79, 2014.

FREIRE, Paulo. Pedagogia do oprimido. 17. ed. Rio de Janeiro: Paz e Terra, 1987.

LAYRARGUES, Philippe Pomier. Para onde vai a Educação Ambiental? O cenário político ideológico da Educação Ambiental brasileira e os desafios de uma agenda políticacrítica contra-hegemônica. Revista contemporânea de Educação, Brasília, nº 14, p. 398-421, agosto - dezembro, 2012.

LEFF, Enrique. Desvelos de la felicidad. Imaginario para repensar la educación en la era de la crisis ambiental. Revista de Ciencias Ambientales (Tropical Journal of Enviromental Sciences), vol. 33, n. 1, p. 40-46, junio, 2007.

HEIDEGGER, Martin. O que é isto - a filosofia. In: Conferências e escritos filosóficos. Tradução: Ernildo Stein. São Paulo: Abril Cultural, 1979.

HEIDEGGER, Martin. Aletheia. In: Ensaios e Conferências. Tradução: Emmanuel Carneiro de Leão. Petrópolis: Vozes, 2002.

HEIDEGGER, Martin. Ser e Tempo. 2. ed. Petrópolis: Vozes, 2007.

GADAMER, Hans-Georg. Verdade e Método II. Complementos e índice. 2. ed. Petrópolis: Vozes, 2004.

MACHADO, Antonio. Proverbios y cantares. Poesías completas. Madrid: Espasa-Calpe, 1983.

ORSTEIN, James Burke Robert. O presente do fazedor de machados. São Paulo: Bertrand Brasil, 1998.

PASSOS, Wagner Valente. Revolução estética e educação ambiental: uma proposta de oposição ao fetichismo, à alienação e à ideologia capitalista. Tese de doutorado. Programa de Pós-Graduação em Educação Ambiental da Universidade Federal do Rio Grande. Rio Grande: FURG, 2018.

SOUZA, Jessé. Os batalhadores brasileiros: nova classe média ou nova classe trabalhadora? Belo Horizonte: Ed. UFMG, 2010.

1 Conta a história da enfermagem que Florence Nightingale, fundadora da enfermagem, tornou-se uma heroína inglesa especialmente por sua atuação na Guerra da Criméia, em 1854. Nas histórias contadas a enfermeiros em formação, o símbolo da profissão, que tem como missão o cuidado, é a lamparina. A lamparina que Nightingale utilizava para iluminar seu caminho até os feridos.

2 A praia do Cassino fica no município de Rio Grande (RS) e é considerada a maior praia do mundo em extensão, com $220 \mathrm{~km}$.

3 Identifico a necessidade de discutir o bem viver.

$4 \quad$ Energia térmica que é transferida entre sistemas em contato, do que possui mais 
para o que possui menos calor.

5 Utilizo a expressão para registrar o corpo como espaço fundante de tal categoria de conhecimento.

6 O autor se utiliza do idioma Quechua para discutir o conhecimento. Runa é o sujeito do conhecimento. 